\title{
Effect of Platelet-Rich Fibrin on The Regeneration Capacity of Bone Marrow Aspirate In Alveolar Cleft Grafting (Clinical and Radiographic Study)
}

\author{
Mohammed Mahgob Mohammed Al-Ashmawy ${ }^{\star}$, Hossam El-Din Mohamed Ali and Abdel Aziz Baiomy Abdullah Baiomy \\ Department of Oral and Maxillofacial Surgery, Faculty of Dental Medicine (Assiut), Al-Azhar University, Egypt
}

"Corresponding autor: Mohammed Mahgob Mohammed Al-Ashmawy, Department of Oral and Maxillofacial Surgery, Faculty of Dental Medicine (Assiut), Al-Azhar University, Egypt, Tel: 02201004227819, 0220552240879; E-mail: maizezo83@gmail.com

Recieved Date: Apr 07, 2017; Accepted Date: Apr 12, 2017; Published Date: Apr 18, 2017

Copyright: (C) 2017 Al-Ashmawy MMM et al. This is an open-access article distributed under the terms of the Creative Commons Attribution License, which permits unrestricted use, distribution, and reproduction in any medium, provided the original author and source are credited.

\begin{abstract}
The present study aimed to evaluate the enhancing effect of platelet-rich fibrin (PRF) on autogenous bone marrow aspirate (BMA) using in a resorbable matrix for repair of alveolar cleft defects. It was conducted on 12 patients (7 males and 5 females) with unilateral alveolar cleft and oronasal leakage. They divided into two random equal groups (group I and II). In group I, alveolar cleft defect packed with a mixture of PRF, $\beta$-Tricalcium phosphate, and BMA, and the same mixture without PRF for group II. Our clinical results revealed that, all patients had uneventful wound healing except some cases in group II. While, densitometric analysis showed a high statistical significant difference between two groups $(p=0.011737)$ at 6 months interval but, at 12 months interval difference was not statistically significant $(p=0.142480)$. Also, volumetric measurements of new bone showed that, there was highly statistical significant difference $(p=0.037997)$ between group I and II at 12 month interval. The present study concluded that PRF may enhance the regeneration capacity of the stem cells when it added to BMA. Thereby, they may accelerate bone regeneration in alveolar cleft defects. Moreover, it may be used as membrane to cover grafted alveolar defect.
\end{abstract}

Keywords: Bone Marrow Aspirate; Alveolar Cleft Grafting; Platelet

\section{Introduction}

Alveolar cleft reconstruction including alveolar bone grafting and closure of oronasal fistula has become an essential process in the treatment of cleft lip and palate patient [1]. It may not only induce the tooth eruption but also stabilize the maxillary arch width and prevent arch collapse, and give osseous support for the nasal alar base and lip [2].

Many sources for bone grafting have been studied such as autogenous bone graft [3,4], alloplastic bone graft [5], and allogenic bone graft [6]. Autogenous bone graft is the most preferred graft although its donor site morbidity. To reduce donor site morbidity related to autogenous bone graft and enhance bone regeneration with reducing post operative resorbtion, growth factors such as bone morphogenic proteins (BMPs) and platelet derived growth factors (PDGF) in combination with different kinds of bone substitutes were examined [7-11].

Platelet-rich fibrin (PRF) is a platelet and leukocyte rich and platelet preparation that concentrate various growth factors and therefore have the potential to be used as regenerative treatment. PRF has some advantages such as no biochemical handling of blood, simplified and cost-effective process, use of bovine thrombin and anticoagulants not required, favorable healing due to slow polymerization, more efficient cell migration and proliferation, and it has supportive effect on immune system $[12,13]$. As a result of these advantages, there are several studies that used PRF as a source for platelet derived growth factors (PDGF) in combination with autogenous bone grafts or synthetic bone materials to enhance bone regeneration [13-15].
With the advent of in vivo tissue engineering methods, mesenchymal stromal cells and osteoprogenitor cells were also considered as a possible treatment solution since they were capable of increasing the number of potentially osteogenic cells. Bone marrow aspirate soaked in absorbable collagen sponge was reported as an alternative method for the closure of human alveolar clefts [16]. In the same side, some studies evaluated recombinant platelet derived growth factors with MSCs and synthetic bone graft and concluded that this mixture may be used as alternative to autogenous bone graft. Drawbacks of these studies, they didn't explain if platelet derived growth factors are essentially effective for this mixture or no. Accordingly, in the present study we assess effect of PRF as a source of growth factors on bone marrow aspirate in resorbable alloplastic matrix for alveolar cleft grafting.

\section{Aim of The Study}

The aim of this study was to evaluate the enhancing effect of PRF on regeneration capacity of human bone marrow aspirate in grafting of congenital alveolar cleft.

\section{Patients and Method}

The present study was conducted on 12 patients $(7$ males and 5 females) complaining from unilateral congenital alveolar cleft and oronasal leakage, requesting treatment of their complaints. Patient ages ranged from 9 to 16 years. They selected from those attending out patient clinic of Oral \& Maxillofacial Surgery Department, Faculty of Dental Medicine Al-Azhar university-Assiut branch. 


\section{Selection criteria}

Selection of the patients was based on the following criteria: patients should have unilateral cleft alveolus with considerable size, accompanied cleft lip and palate should be pretreated, absence of any systemic disorders that may influence the course of wound healing, absence of any blood disorders which might cause complications after the bone marrow aspirate procedures, also Syndromic cases were excluded.

\section{Patients grouping}

The patients were divided randomly into two equal groups; group I comprised 6 patients grafted with composite of $\beta$-Tricalcium phosphate granules (Bioresorb, sybron implant solutions $\mathrm{GmbH}$ Bremen, Germany), PRF and bone marrow aspirates. Group II comprised 6 patients grafted with $\beta$-Tricalcium phosphate mixed with bone marrow aspirate cells only.

\section{Preoperative procedures}

Preoperative procedures included history taking, intraoral and extraoral clinical examination, patient photograph from various views, study cast, and CT scans to assess and measure the alveolar cleft volume before surgery. Orthodontic palatal expansion was preformed for cases presented with collapsed arch firstly.

\section{Operative procedures}

Patients were prepared for surgery with the basic traditional method. All operations were done under general anaesthesia. Preparation of the recipient sites were similar in all patients, whereas, the labial mucoperiosteal flaps were reflected from bone and sutured to each other then the nasal mucosa was reflected to close nasal mucosa. The palatal mucoperiosteal flaps were reflected and sutured to each other to repair the palatal mucosa of palatal side of the cleft if needed.

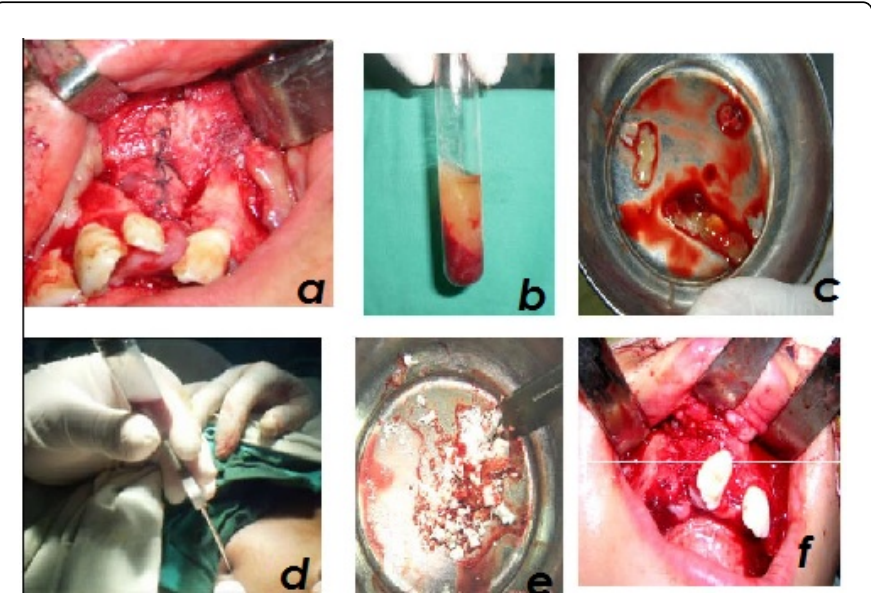

Figure 1: Photograph showing treatment plan of group I, (a) Suturing nasal mucosa (b) Test tube after centrifugation and separation of PRF (c) Collection of PRF in sterile dish (d) Bone marrow aspiration (e) Mixing of $\beta$-Tricalcium phosphate, PRF and bone marrow aspirates (f) Packing of the mixture in the alveolar defect.
During preparation of the recipient site, in group I the required amount of blood was aspirated and centrifuged for PRF preparation according to Choukroun's method [17-19] and beside that the required amount of bone marrow was aspirated from the ilium. PRF gel (4-6 $\mathrm{ml}$ ) and bone marrow aspirate (1-2 ml) were mixed with a mount of $\beta$ Tricalcium phosphate granules, according to size of defect and placed in recipient bed. In group II, the same mixture without PRF packed in the recipient defect. In group I, PRF gel was used to mix with BMA, and $\beta$-Tricalcium phosphate granules and as a cover for the defect after packing of mixture. Finally for closing of the wound in both groups, labial and palatal flaps were raised and mobilized to have a watertight tension free closure of the mucosa by interrupted $4 / 0$ vicryl sutures (Figure 1).

\section{Postoperative Care and Follow-Up}

\section{Postoperative care}

Firstly, postoperative medications and instructions were described for patients to avoid postoperative complications such as infection, and edema. The patients were closely observed daily in the first week and then asked to attend for follow-up at 2nd, 3rd and 4th weeks and then after 6 months and one year postoperatively for clinical and radiographic evaluation.

\section{Postoperative clinical evaluation}

Clinical evaluation involved observation of the following clinical parameters:

- Wound examination for suture breakdown, dehiscence, swelling, infection, edema, hematoma, graft rejection and presence of oronasal fistula.

- Patient asked for pain or any nasal regurgitation.

\section{Postoperative radiographic assessment}

Radiographic assessment postoperatively was done at the end of six and twelve month. Axial and coronal CT scans were made at about 0.5 $\mathrm{mm}$ section for each case to assess evidence of bone formation, presence of any bony bridging across the defect, volume, density, and the height of the newly formed bone.

\section{Bone density measurement}

Bone density was measured for each case on the axial cuts. The bone density was measured using Bioquant 15.1 software (BIOQUANT Image Analysis Corporation, www. bioquant. com), that measure average density for the target area. The bone density was measured for each patient at 6 and 12 month postoperatively.

\section{Cleft volume measurement and bone fill measurement}

Preoperative radiographic examinations included CT scans were carried out for each patient for determination of alveolar cleft volume on CT axial sections. The volume of the defect remaining around the newly formed bone was calculated and then subtracted from the total measured cleft volume to have the volume of the newly formed bone at 12 month. Volume measurments were done with Millensys software (Millensys Infinite Ideas software: MiniViewer 2008, www. millensys.com.). All previous data were collected and statistically analyzed. 
Citation: Al-Ashmawy MMM, Ali HEM, Baiomy AABA (2017) Effect of Platelet-Rich Fibrin on The Regeneration Capacity of Bone Marrow Aspirate In Alveolar Cleft Grafting (Clinical and Radiographic Study). Dentistry 7: 428. doi:10.4172/2161-1122.1000428

Page 3 of 5

\section{Statistical analysis}

Numerical data were presented as mean and standard deviation values. One-way ANOVA (Analysis of Variance) was used to compare between two groups. Duncan's post-hoc test was used for pair-wise comparison between the means when ANOVA test is significant. Paired t-test was used to study the changes by time in each group. The significance level was set at $\mathrm{P} \leq 0.05$. Statistical analysis was performed with SPSS $17.0^{\circ}$ (Statistical Package for Scientific Studies) for Windows.

\section{Results}

\section{Clinical evaluation}

Postoperative wound healing in both groups was uneventful except 2 cases of group II showed dehiscence and stitch abscess at releasing incision of mucoperiosteal flap with bare area of bone lateral to the defect, which was treated with vigorous mouth wash application, in addition to patient instruction of good oral hygiene. No bleeding was observed in both groups and postoperative swelling subsided after 7 to 10 days in both groups. At 12 month interval, all patients obtained retention of the alveolar arch and stabilization of the teeth adjacent to the cleft. All oronasal fistulas were closed.

\section{Radiographic results}

Radiographic CT scans were done at 6 and 12 month postoperatively to measure the regenerated bone density. Volume of regenerated bone was measured only at 12 months postoperatively (Figure 2).

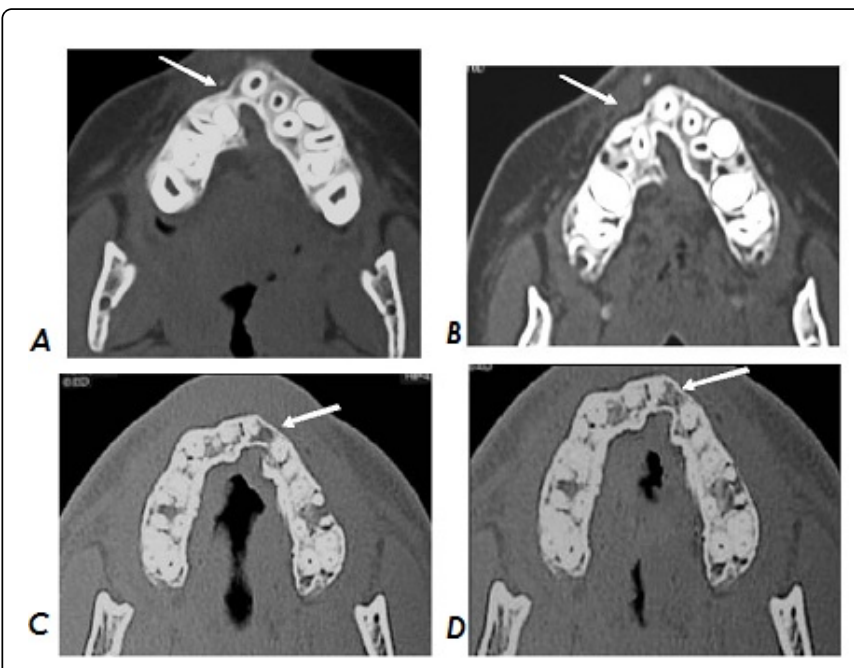

Figure 2: A- Photo-radiograph of group I showing postoperative axial CT section representing bone bridging of alveolar defects at 6 month interval. B- Photo-radiograph of group I at 12 month interval. C- Photo-radiograph of group II showing postoperative axial CT section representing bone bridging of alveolar defects at 6 month interval. D- Photo-radiograph of group II at 12 month interval.

\section{Bone density}

At six month the mean of group II was (184 pixels) less than the mean of group I (193 pixels). Therefore, there was a highly statistically significant difference between two groups $(p=0.011737)$. This means that, newly formed bone of group I was significantly denser than group II at the same interval. At 12 months, the mean of the group I was (243 pixels) more than the mean of group II (239 pixels). These showed a difference between means of two groups but this difference was not a statistically significant $(\mathrm{p}=0.142480)$ (Table 1$)$.

\begin{tabular}{|l|l|l|l|l|l|}
\hline \multicolumn{2}{|c|}{} & Mean & S.D & t -test & P \\
\hline \multirow{2}{*}{$\mathbf{6 ~ \mathbf { ~ m }}$} & Group I & 193 & 7.410 & & \\
\cline { 2 - 4 } & Group II & 184 & 8.303 & \multirow{2}{*}{2.965335} & $0.011737^{*}$ \\
\hline \multirow{2}{*}{$\mathbf{1 2} \mathbf{~ m}$} & Group I & 243 & 12.95 & & \\
\cline { 2 - 4 } & Group II & 239 & 9.241 & \multirow{2}{*}{1.71466} & 0.142480 \\
\hline
\end{tabular}

Table 1: Showing comparison of mean bone density of two groups at 6 and 12 month in addition to standard deviation (S.D) and t-test for each interval and $\mathrm{p}$ value (Significant at $\mathrm{P} \leq 0.05$ ).

\section{Bone Volume Measurements}

The measurements were carried out postoperatively at 12 months for both groups. The percentages of newly formed bone ranged from $62.23 \%$ to $90.68 \%$ with a mean percentage of $75.80 \%$ for group I and from $32.96 \%$ to $60.87 \%$ with mean percentage of newly formed bone of $47.80 \%$ in group II. The comparison of the postoperative newly formed bone between two groups showed that, there was highly statistical significant difference between both groups. Where, the mean of regenerated bone in group I was $0.841 \mathrm{cc}$ and in group II was $0.434 \mathrm{cc}$ and the $\mathrm{p}$ - value was 0.041 . These results revealed that a mixture of BMA, PRF, and $\beta$-Tricalcium phosphate was superior to the composite of BMA, and $\beta$-Tricalcium phosphate without PRF in terms of formation of a higher volume of regenerated bone. Moreover, the mixture which contains PRF gave denser and more amount of newly formed bone (Table 2).

\begin{tabular}{|l|l|l|l|l|}
\hline Mean & S.D & t -test & \multicolumn{2}{|l|}{ P } \\
\cline { 1 - 2 } Group 1 & 0.841 & 0.2216 & & $0.041^{*}$ \\
\cline { 1 - 2 } Group 2 & 0.443 & 0.2181 & -2.4327 & \\
\cline { 1 - 1 } Significant at P $\leq 0.05$ & & \\
\hline
\end{tabular}

Table 2: Showing means, standard deviation (S.D), t-test and p-value of postoperative regenerated bone at 12 months in both groups.

\section{Discussion}

The alveolar cleft reconstruction of bone defects in cleft lip and palate patients has been a controversial issue since the first reported bone graft series in 1955. Alveolar cleft grafting has different philosophies regarding time of the graft (primary, secondary or late secondary), grafting materials (autogenous, allogenic, alloplastic or tissue engineered materials) and presurgical versus post surgical orthodontic treatment [20].

In the present study, congenital alveolar cleft defects was compared when grafted with a composite of $\beta$-Tricalcium phosphate, platelet rich 
fibrin and bone marrow aspirate (group I ) versus a composite of $\beta$ Tricalcium phosphate, and bone marrow aspirate (group II) in cleft grafting. Aim of this comparison was evaluation enhancement effect of PRF on BMA cells and wound healing.

Ages of patients in the present study were ranged from nine two 16 years with a mean age of 11.4 years in group one and 11.1 years in group two. This choice was done to avoid any sagittal or transverse maxillary growth disturbance and providing a predictable mature viable stock of bone in the alveolus with adequate cross sectional width for tooth eruption and orthodontic tooth movement and bony support for dental implant or fixed dental bridge later on. Also, this concept is in accordance with many authors who suggested secondary alveolar bone grafting is the most appropriate time for bone grafting [21-23].

In the current search, group I showed eventful healing and closure of all oronasal fistulae. But, at comparison of both groups increase in the time of edema and occurrence of dehiscence in two cases in group II was observed. This observation could be attributed to absence of PRF in group II. Because of PRF membranes protects the surgical site; promotes soft tissue healing; and when its fragments mixes with graft material, it functions as a "biological connector" between the different elements of graft and acts as a matrix which supports neoangiogenesis, capture of stem cells, and migration of osteoprogenitor cells to the center of graft. This explanation is in agreement with studies of Toffler et al and Simonpieri et al. [12,13].

In this study, the alveolar cleft defect and the regenerated bone volumes were assessed preoperatively and 12 month postoperatively using special software. The measurements were done on the axial, coronal and 3D CT sections to have the average volume of the defects and regenerated bone for each case in both groups. This matched with authors which compared CT with conventional radiography, and concluded that CT offers better accuracy without anatomic superimposition and improved image quality [24,25].

In the present study, CT radiographic assessment at six month revealed that in group II an evident newly formed labial and palatal plates of bone with decrease in the density and arrangement of bone trabeculae in the center of the defects at this time. While, the group I at the same time showed adequate normal bone formation with adequate normal cortex and well arranged bone trabeculae in the center. In the same manner, at 12 month maturation in group I was more evident that in group II and the density was similar the normal adjacent bone at this time. Although, analysis data of denistromotric evaluation showed no significant difference between both groups at 12 month intervals, that of volumetric evaluation showed a high statistically significant difference between both groups.

Our results matched with Behania et al. [18] study although short time evaluation of this study. In the opposite side, Khojasteh et al. [17] concluded that mesenchymal stem cells enhance bone regeneration in critical size defects more than platelet derived growth factors. This in the same direction with Schmitiz and Hollinger [26] results that pointed to platelet derived growth factors is inhibitory to osteoblastic cells if delivered in a continuous form and increase bone resorbtion. This difference is because of these studies used PRP as a source for growth factors while in our study PRF was a source for growth factors delivery. This explanation matched with. Dohan et al. [27] which proved a slower release of growth factors from PRF than PRP lead to better healing properties with PRF. Moreover, the fibrin matrix is better organized; it is able to more efficiently direct stem cell migration and the healing program.
On the basis of the present study the following conclusion can be drawn that a combination of human bone marrow aspirate with PRF may enhance the regeneration capacity of the cells in alveolar cleft grafting leading to acceleration bone healing in alveolar defect but further clinical studies are needed to find a predictable way to ensure success.

\section{References}

1. Witsenburg B (1985) Reconstruction of anterior residual bone defects in patients with cleft alveolus and palate. A review. J Maxillofac Surg 13: 197.

2. Hartel J, Pogl C, Henkel KO (1999) Dental implants in alveolar cleft patients: A retrospective study. J Craniomaxillofac Surg 27: 354.

3. Eufinger H, Leppanen $\mathrm{H}$ (2000) Iliac crest donor site morbidity following open and closed methods of bone harvest for alveolar cleft osteoplasty. J Craniomaxillofac Surg 28: 31-38.

4. Sindent-Pedersent S, Enemark H (1990) Reconstruction of alveolar clefts with mandibular or iliac crest bone grafts: a comparative study. J Oral Maxillofac Surg 48: 554-558.

5. Matsui Y, Ohta M, Ohno K, Nagumo M (2006) Alveolar bone graft for patients with cleft lip/palate using bone particles and titanium mesh: a quantitative study. J Oral Maxillofac Surg 64: 1540-1545.

6. Filho O, Ozawa T, Bachega C, Bachega M (2013) Reconstruction of alveolar cleft with allogenous bone graft: clinical considerations. Dental Press J. Orthod 18: 6.

7. Oyama T, Nishimoto S, Tsugawa T, Shimizu F (2004) Efficacy of PlateletRich Plasma in Alveolar Bone Grafting. J Oral Maxillofac Surg 62: 555-558.

8. Marx RE, Carlson ER, Eichstaedt RM, Schimmele SR, Strauss JE (1998) Platelet-rich plasma: growth factor enhancement for bone grafts. Oral Surg Oral Med Oral Pathol Oral Radiol Endod 85: 638-646.

9. Marx RE (2004) Platelet-rich plasma: evidence to support its use. J Oral Maxillofac Surg 62: 489-496.

10. Moghadam HG, Urist MR, Sandor GK, Clokie CM (2001) Successful mandibular reconstruction using a BMP bioimplant. J Craniofac Surg 12: 119-127.

11. Mohan S, Baylink DJ (1991) Bone growth factors. Clin Orthop Relat Res 263: 30-48.

12. Toffler M, Toscano N, Holtzclaw D, Corso MD, Dohan Ehrenfest DM (2009) Introducing Choukroun's platelet rich fibrin (PRF) to the reconstructive surgery milieu. J Implant Adv Clin Dent 1: 21-30.

13. Simonpieri A, Jimbo R, Vervelle A (2012) Current Knowledge and Perspectives for the Use of Platelet-Rich Plasma (PRP) and Platelet-Rich Fibrin (PRF) in Oral and Maxillofacial Surgery Part 2: Bone Graft, Implant and Reconstructive Surgery. Current Pharmaceutical Biotechnology 13: 1231-1256.

14. Finchk Y, Baykul T (2013) Secondary closure of alveolar clefts with mandibular symphyseal bone grafts and with platelet-rich fibrin under local anesthesia: three case reports. J contemporary dental practice 14 : 751-753.

15. Diss A, Dohan MD, Mouhyi J, Mahler P (2008) Osteotome sinus floor elevation using Choukroun,s platelet-rich fibrin as grafting material: a 1year prospective pilot study with micro threaded implants. Oral Surg Oral Med Oral Pathol Oral Radiol Endod. 105: 572-79.

16. Gimbel M, Ashley RK, Sisodia M, Gabbay J, Wasson KL (2007) Repair of alveolar cleft defects: reduced morbidity with bone marrow stem cells in a resorbable matrix. J Craniofac Surg 18: 895-901.

17. Khojasteh A, Eslaminejad MB, Nazarian H (2008) Mesenchymal stem cells enhance bone regeneration in rat calvarial critical size defects more than platelet-rich plasma. Oral Surg Oral Med Oral Pathol Oral Radiol Endod 106: 356-362.

18. Behnia H, Khojasteh A, Soleimani M, Tehranchi A, Atashi A (2012) Repair of alveolar cleft defect with mesenchymal stem cells and platelet derived growth factors: A preliminary report. Journal of Cranio-MaxilloFacial Surgery 40: 2-7. 
Citation: Al-Ashmawy MMM, Ali HEM, Baiomy AABA (2017) Effect of Platelet-Rich Fibrin on The Regeneration Capacity of Bone Marrow Aspirate In Alveolar Cleft Grafting (Clinical and Radiographic Study). Dentistry 7: 428. doi:10.4172/2161-1122.1000428

Page 5 of 5

19. Choukroun J, Diss A, Simonpieri A, Girard MO, Schoeffler C, et al. (2006) Platelet-rich fibrin (PRF): A second-generation platelet concentrate. Part V: Histologic evaluations of PRF effects on bone allograft maturation in sinus lift. Oral Surg Oral Med Oral Pathol Oral Radiol Endod 101: 299-303.

20. Hartel J, Pogl C, Henkel KO (1999) Dental implants in alveolar cleft patients: A retrospective study. J Craniomaxillofac Surg 27: 354

21. Kalaaji A, Lilja J, Friede H, Elander A (1996) Bone grafting in the mixed and permanent dentition in cleft lip and palate patients: long-term results and the role of the surgeon's experience. J Cranio-Maxillofac Surg 24: 29.

22. Pradel W, Reimer BL, Mc-Neir D (2008) Spontaneous tooth eruption after alveolar cleft osteoplasty using tissue engineered bone: a case report. Oral Surg Oral Med Oral Pathol Oral Radiolo Endodo 105: 440.

23. Takahashi T, Sorensen H, Weis-Fogh U (2008) Long-term follow-up of dental implants placed in a grafted alveolar cleft: evaluation of alveolar bone height. Oral Surg Oral Med Oral Pathol Oral Radiolo Endodo 105: 297.

24. Van AJW, Baart JA, Prah-Andersen B (1994) Computed tomography in evaluation of early secondary bone grafting. Int J Oral Maxillofac Surg 23: 132.

25. Dado DV, Rosenstein SW, Alder ME (1997) Long-term assessment of early alveolar bone grafts using three-dimensional computer assisted tomography: A pilot study. Plast Reconstr Surg 99: 1840.

26. Schmitz JP, Hollinger JO (1972) The biology of platelet-rich plasma. J Oral Maxillofac Surg 59: 1119.

27. Dohan DM, Choukroun J, Diss A, Dohan SL, Dohan AJ (2006) Plateletrich fibrin (PRF): a second-generation platelet concentrate. Part II: platelet-related biologic features. Oral Surg Oral Med Oral Pathol Oral Radiol Endod 101: e45-e50. 